\title{
The history of transaction cost economics and its recent developments
}

\author{
ŁUKASZ HARDT \\ University of Warsaw \\ Polish Academy of Sciences
}

\begin{abstract}
The emergence of transaction cost economics (TCE) in the early 1970s with Oliver Williamson's successful reconciliation of the socalled neoclassical approach with Herbert Simon's organizational theory can be considered an important part of the first cognitive turn in economics. The development of TCE until the late 1980s was particularly marked by treating the firm as an avoider of negative frictions, i.e., of transaction costs. However, since the 1990s TCE has been enriched by various approaches stressing the role of the firm in creating positive value, e.g., the literature on modularity. Hence, a second cognitive turn has taken place: the firm is no longer only seen as an avoider of negative costs but also as a creator of positive knowledge.
\end{abstract}

Keywords: transaction cost economics, Oliver Williamson, theory of the firm, modularity literature, cognitive turn

JEL Classification: B21, B31, D21, D23, D83

Transaction cost economics (TCE) has a long past since what we generally speak of as 'transaction costs' have been present in economic discourse for centuries. The past of TCE is rich in metaphors describing the idea of transaction costs, but the one with the most profound impact on the later development of TCE was the notion of frictions. That metaphor is strongly connected to the further metaphor of the market as a machine whose deviations from ideal functioning is characterized by frictions (e.g., Walras 1893). Therefore, the study of the past of TCE is guided by the study of its metaphors and particularly that of mechanical

AUTHOR'S NOTE: I would like to thank the editors of EJPE and two anonymous referees for valuable comments and suggestions. I would also like to thank Matthias Klaes for stimulating discussions on some parts of the paper. This research was partially financed by a grant from the Polish Ministry of Science and Higher Education (Grant no. N N112 127936). All errors are my own. 
friction. The past of TCE was not encapsulated in a particular research program, but rather in uncoordinated attempts to give the elementary idea of "costly exchange" an operational counterpart. ${ }^{1}$

For centuries that elementary idea had been conceptualized as just costs of transportation (e.g., Aristotle's Politics and Smith's Wealth of nations). ${ }^{2}$ Then, in the nineteenth century, Menger introduced the concept of friction into his Grundsätze der Volkswirtschaftslehre where it stands for various difficulties in the process of price formation. The growing popularity of the friction metaphor made it a useful concept for explaining given theoretical model's failures-economists simply introduced frictions (Klaes 2000a). That was the case for example in monetary economics at the beginning of the twentieth century, when economists considered why people hold onto cash rather than profitable assets.

It was John Hicks who first disagreed with general friction-based explanations: "The most obvious sort of friction, and undoubtedly one of the most important, is the cost of transferring assets from one form to another" (Hicks 1935, 6). Subsequently, in 1940, Tibor Scitovsky introduced the label of 'transaction costs' into the economic vocabulary (Hardt 2006). In the meantime Ronald Coase published his 1937 paper in which he attributed the existence of the firm to the cost of using the price mechanism (Coase 1937, 390).

It should be clear therefore, that TCE, understood as the study of the economic consequences of "costly exchange", existed a long time before becoming a research program within the framework of economics. It has a long past but as a science it has a short history. ${ }^{3}$ That history began in the 1970s with the work of Oliver Williamson. The first appearance of the term 'transaction cost economics' was in the title of Williamson's article in 1979, "Transaction cost economics: the governance of contractual relations" in the Journal of Law and Economics and, as far as the study of transaction costs usually leads to the study of institutions,

\footnotetext{
${ }^{1}$ I use the term 'research program' in the entire article not in a strict Lakatosian sense, but merely as a theory or a set of theories developed in order to solve particular problems (for a further discussion, see the final paragraph of the forth section).

${ }^{2}$ The term 'elementary idea' is used here in the sense of Lovejoy (1982), namely as an idea present in various historical époques and in different cultures. Treating transaction costs as an elementary idea leads us to the conclusion that it is of crucial importance for economics as a whole, since "the number of essentially distinct philosophical [here: economic] ideas is decidedly limited" (Lovejoy 1982, 4).

${ }^{3}$ A reconstruction of the past of TCE can be found in Klaes 2000a; 2000b; 2001a.
} 
he is also the father of the term 'new institutional economics', in Markets and hierarchies, 1975.

As it is indicated in the title of this article, my goal here is to reconstruct the history of TCE: the approach within economic theory emerging from Williamson's contributions in the 1970s. Since "[...] in order to evaluate the past [history] properly the historian of science must know the present" (Bachelard 1951, 9), I will try to find a theoretical bridge between the history of TCE-particularly of its emergence (the Williamsonian TCE of the 1970s)-and its recent developments. Consequently, I reconstruct the rise of Williamsonian TCE and claim that his approach, lying at the intersection of economics and organization, is to a great extent responsible for the first cognitive turn in economics: namely the limited transformation of the so-called mainstream economics (henceforth, ME) due to the study of economic activity as undertaken by agents characterized by limited cognitive capacity. ${ }^{4}$

First the character of Williamsonian TCE is analyzed and it is argued that what distinguishes his theory is his treating the firm as an avoider of negative (transaction costs). The underlying logic of the development of TCE can be described as a move from treating the firm as an avoider of negative (costs) towards conceptualizing the firm as a creator of positive (knowledge). I show that this was due to the (re)introduction of knowledge related problems into the realm of TCE following the incorporation of those elements of Simon's legacy which did not enter TCE in the 1970s. ${ }^{5}$

I describe this late incorporation of some elements of the Carnegie legacy as a second cognitive turn in TCE. Interestingly, as the first cognitive turn allowed for the limited incorporation of TCE into economic orthodoxy, the second one moved TCE back towards economic

\footnotetext{
${ }^{4}$ I define here mainstream economics simply as orthodox economic thought. For the purposes of this paper heterodoxy is understood as non-orthodoxy, where orthodoxy denotes the research perspective based on the framework of maximizing behavior. The further a given theoretical approach is from a maximizing (or cost-minimizing) framework, the more heterodox it is.

${ }^{5}$ The inveteracy of knowledge issues is an important distinguishing feature of modern TCE as opposed to the Williamsonian approach of the 1970s. In that sense TCE is not just one of many approaches dealing with the issue of incomplete information. If we treat information just as "data organized into a meaningful pattern", then even in the situation of possessing perfect information we may still have imperfect knowledge (treating knowledge as "information with a layer of intellectual analysis", e.g., beliefs about causality, see Hislop 2005, 16). That is why limited cognitive capacity leads to imperfect knowledge even in the presence of perfect information.
} 
heterodoxy (Groenewegen and Vromen 1996). In other words, recent TCE literature can be seen as a more "new institutional" approach than was the case for Williamson's early writings, described by Dugger (1983, 96) as just "a more realistic and sophisticated neoclassicism". The closeness of recent TCE to "new institutionalism" is mainly due to the fact that nowadays its research apparatus is only partially built on the "economizing on transaction costs" principle. In that sense TCE, I claim, is more heterodox than in the early 1970 s. $^{6}$

\section{THE FIRST COGNITIVE TURN: THE EMERGENCE OF TCE}

While the term 'transaction costs' appeared in the economic literature relatively late, the notion of 'transaction cost economics' entered into economics even later, that is, in the work of Oliver Williamson from the late 1970s. Before that, the approach emerging from Coase's (1937) "The nature of the firm" was described as transaction cost reasoning, transactional paradigm or transaction cost approach. Surprisingly, even in his now classic papers from the early 1970s Williamson did not use the term 'transaction cost economics'. For Williamson the transaction cost approach was at that time outside the domain of mainstream economics, namely the orthodox economics based on the work of Arrow and Debreu.

In Markets and hierarchies, Williamson expresses his doubts about the place of transaction cost reasoning within economic theory as follows: "Whether such an approach qualifies as economics is problematic" $(1975,248)$. A few years later he adds: "[...] the origins of transaction cost theory must be sought in influences and motives that lie outside the normal domain of economics" (Williamson 1981b, 1538). In other words, in the economics built on the general equilibrium framework any attempt to incorporate transaction costs into the realm of ME would be treated as a heresy, and the term 'transaction cost economics' would seem an oxymoron.

In the 1970s, however, something had changed in ME: economic theory started to become more pluralistic again (as it had been in the 1920 s and the 1930s). ${ }^{7}$ On the one hand, many economists failed in their attempts to build a "whole" economic theory on the general equilibrium

\footnotetext{
${ }^{6}$ See Hodgson 1993, 12.

' I use the word 'pluralistic' here in a broad sense, namely that economics started to be rich in various theories (plurality of theories) and that economists gradually started to treat the growing plurality of theories as a positive phenomenon. See also Mäki 1997.
} 
framework, e.g., because of the impossibility of formulating the socalled microfoundations of macroeconomics-the implication of the Sonnenschein-Mantel-Debreu theorem (Sent 2006). On the other hand, the introduction of transaction costs into the world of Arrow-Debreu resulted in claims such as that "[...] different social arrangements result in different transaction technologies purely as a result of legal ways of protecting property rights" (Kurz 1974, 4), i.e., that the set of possible transaction opportunities depends on the institutional framework of the economy. Consequently, ME has been transformed into various complementary approaches based on game theory, bounded rationality, experimental methods, and last but not least transaction cost reasoning. ${ }^{8}$ In the late 1970 s putting the term 'transaction cost' together with the word 'economics' became not only possible, but also desirable. The long past of TCE was over, and the history of TCE had begun.

This section is organized as follows. First, the emergence of Williamsonian TCE, described as the first cognitive turn in economics, is reconstructed. Then, in a second subsection, his theory is presented, focusing on his conceptualization of a firm as an avoider of negatives.

\section{The rise of Williamsonian TCE}

In the 1950s and 1960s the neoclassical theory of the firm started to be widely criticized for its unrealistic assumptions. The assumption of profit maximization was questioned as well as that of a firm's perfect information about market conditions. Katona (1951) claimed, for instance, that firms do not maximize profits, but act in order to satisfy managers' various ambitions. In the same way, argued Papandreou (1952), firms just maximize a so-called "general preference function", which aggregates the individual aspirations of members of an organization. Rothschild (1947) went even further and claimed that a firm's raison d'être is just to survive. Others did not reject the importance of making profits, but instead of the pure profit maximization assumption they preferred to talk about achieving satisfactory profits (e.g., Gordon 1948; Margolis 1958).

Such critique of the neoclassical theory of the firm opened up the black box of the Marshallian representative firm and shifted economists' focus of attention towards the study of the internal structure of the

8 I do not claim here that the so-called degeneration or in other words great transformation of economics was only due to the two above mentioned facts. For an in-depth study of the reasons for the growing pluralism within ME, see Sent 2006; Colander, et al. 2004. 
firm. Consequently, two kinds of theories emerged: those dealing with the issue of designing an incentive structure within the firm that would maximize the firm's chances of surviving in the market (e.g., Bernard 1938; Simon, et al. 1950); and an approach focusing on the issue of decision making within organizations, which took its origin from cognitive psychology (e.g., Simon 1957a). What links these two kinds of theories is a departure from the perfect rationality assumption and its replacement by the claim that individuals are characterized by bounded rationality: "[they] are intentionally rational, but only to a limited extent" (Simon 1957b, xxiv). Economic man is substituted by organizational man with limited computational and cognitive capacity (Simon 1978). For Herbert Simon the key to understanding the functioning of the economy is an analysis of the decision making process:

The most important data that could lead us to an understanding of economic processes and to empirically sound theories of them reside inside human minds. Accordingly, we must seek to discover what went on in the heads of those who made the relevant decision (Simon 1997, 70-71).

Simon's research, particularly his concept of bounded rationality, had a profound impact on other economists working at Carnegie, and made the rapid development of organizational theory and behavioral economics possible. Two important features of research in the area of organizational theory undertaken at Carnegie were its interdisciplinary character and concern with empirical problems. Richard Cyert, one of the main proponents of behavioral economics at Carnegie, describes the character of the economic theory developed at Carnegie in the 1950s and the 1960s as follows:

If you are doing behavioral economics you have to think about actual behavior and you also have to have the ability to move to the field of organization theory, and to borrow ideas from other fields too, such as psychology [...]. On the theoretical level it is important to learn to deal with bounded rationality and uncertainty. You have to deal with the real world (Interview with Cyert, in: Augier and March, 2002, 6).

The above statement by Cyert may suggest that economics at Carnegie was quite heterodox and was in opposition to ME, but that was not the case. One should note that apart from the behaviorist group there was also a strong ME group dealing with issues such as rational 
expectations and the theory of effective markets (for example, Franco Modigliani, John Muth, Merton Miller, Allan Meltzer, and later also Robert Lucas, Thomas Sargent, and Edward Prescott). Due to the relatively small number of economists at Carnegie, people from the two groups exchanged ideas and they quite often had very heated debates (Klaes 2001b). That intellectual atmosphere made Carnegie "an incredible place at which to be a student" says Oliver Williamson, a graduate student at the Graduate School of Administration at Carnegie in the late 1960s. In an interview from 1988 he adds:

The Carnegie experience was extraordinary. I really enjoyed it [...], it was just such an interesting place to be. Interdisciplinary work was going on [which] included a good deal of work in organization theory [...]. I especially found the intersection of economics and organization fascinating, and I felt that there would be a lot of research opportunities here (Williamson 1990, 117).

Williamson's $\mathrm{PhD}$ dissertation entitled The economics of discretionary behavior: managerial objectives in a theory of the firm is situated just at the intersection of economics and organization:

[...] although the objective function of the firm was reformulated in favor of realism in motivation, I worked out of a maximization rather than a satisficing setup. The dissertation therefore reflected some of the tensions between behavioral economics and orthodoxy (Williamson 1996, 150).

The research strategy of Oliver Williamson was to use the behavioral assumptions of organizational theory combined with the quantitative and marginal analytical framework of neoclassical economics (Allen 1999). The following statement by Williamson from "Hierarchical control and optimum firm size" clearly summarizes his research strategy:

The strategy of borrowing behavioral assumptions from the organization theory literature and developing the implications of the behavior observed within the framework of economic analysis would seem to be one which might find application quite generally. Combining these two research areas so as to secure access to the strengths of each would thus appear to be quite promising (Williamson 1967, 135).

For Williamson, the theories and concepts of organization theory literature including those of Simon's behavioral economics were related 
to the analysis of individual decision making and hence had a very microeconomic character. However, the majority of organization theory's concepts were defined so broadly that it was nearly impossible to use them in empirical research. It became evident for Williamson that there was a need to translate the behavioral concepts of Carnegie into the language of economics (Simon 1997, 38).

In the late 1960s Williamson tried to explicate the rationale for vertical integration, but he could not find the answer within the framework of ME. That question is similar to the one posed by Coase in "The nature of the firm", but the answer given by Williamson is slightly different from that of Coase. Although Williamson was deeply convinced that the existence of market exchange costs was important for explaining the emergence of firms, "[he] was not persuaded of the possibilities inherent in the transaction cost approach" (Williamson 1990, 117). Then, while preparing a series of seminars on the theory of vertical integration requested by Julius Margolis, he discovered that the reasons for integration lie in the behavioral characteristic of contracting actors and first of all in bounded rationality:

Bounded rationality is one of them. I don't know if I defined opportunism at the time, but we focused on two critical issues which are close to opportunism, namely limitations associated with promises and the fact that some promises need institutional support (Williamson 1990, 118).

Consequently, the problem of opportunistic behavior combined with that of bounded rationality arising in the situation of bilateral monopoly (small-numbers exchange) and uncertainty emerged as the defining features of his analytical framework. Subsequently, Williamson translated ideas from organization literature into concepts observable in the functioning of firms and markets: Simonian bounded rationality gave a theoretical foundation for formulating the idea of incomplete contracts and opportunism, and the search theories of Cyert and March (1964)-e.g., myopic search, trial-and-error learning, and local searchenabled Williamson to develop the concept of "feasible foresight". Next, he combined that conceptual framework with the "classical" assumption of neoclassical economics, namely that of cost minimization. The emerging transaction cost economics, here described also as Williamsonian TCE, followed. The first paper in which he used that framework was "The vertical integration of production: market failure 
considerations" (1971). Twenty years after its publication he says: "I really feel, at the time when I wrote the paper, that I cracked the problem. This was obviously a certain exaggeration. But I did have a sense that this reformulation [of concepts] really got to some of the basic issues" (Williamson 1990, 119).

The organizational theory of Carnegie was the first attempt within (broadly defined) economics of building a connection between (cognitive) psychology and (old behavioral) economics (Sent 2004, 739740). That was possible mainly due to Simon's contribution to the socalled cognitive revolution: the successful attempt to bring psychological insights into the realm of economic theory and simultaneously to limit the role of behaviorism. ${ }^{9}$ But still, organizational researchers at Carnegie remained quite dissatisfied with mainstream economics. Simon, for instance, left the Carnegie Graduate School of Industrial Administration in the 1970s for the psychology department of the same university, noting: "My economist friends have long since given up on me, consigning me to psychology or some other distant wasteland" (Simon 1991, 385).

Sent (2004) even claims that due to its distance from ME the organizational theory of Carnegie had a very limited impact on economic theory of the 1960s and 1970s; however, the emergence of Williamsonian TCE proves the contrary. There is no doubt that TCE had a profound impact on the state of economic theory in the 1970s, and that it is partly responsible for its current plurality. Moreover, there is no doubt that the rise of TCE in the 1970s was only possible due to the Carnegie revolution of the incorporation of psychological concepts into economics. In that sense, Carnegie, by making the rise of TCE possible, played an important role in transforming ME, and hence the rise of TCE can be treated as the first cognitive turn in economics.

\section{The firm as an avoider of negatives in Williamsonian TCE}

Every theory of the firm must answer the following question: why do firms exist? (Holmstrom and Tirole 1989, 165). According to Williamson, firms emerge when making transactions internally (within the firm) is

\footnotetext{
${ }^{9}$ One should note that the cognitive turn described here can be treated as an important step in the process of enriching economics with various ideas from the cognitive sciences. That turn is more advanced than "[...] the cognitive (half-) turn made at Cowles" (Mirowski 2001, 451), because the "(half-) turn" was mainly due to the incorporation of informational issues into the realm of economics (e.g., Marschak's work), and not the knowledge ones, as in the case of Simon's contributions.
} 
cheaper than externally (on the market). That is similar to Coase's now famous statement that "the main reason why it is profitable to establish a firm would seem to be that there is a cost of using the price mechanism" (1937, 390); however, in "The nature of the firm" we do not find an in-depth analysis of the reasons for the positive costs of market exchange. Coase (1937) writes about "the cost of discovering what the relevant prices are", and "the cost of negotiating and concluding a separate contract", but does not elaborate extensively on these concepts, nor give any operational measures of transaction costs. Moreover, in his 1937 paper he does not study the interplay between institutions and transaction costs:

[...] as I came to realize when I wrote "The problem of social cost", all these interrelationships [between institutions and transaction costs] are affected by the state of law, which also needs to be taken into account in the analysis. But it is a theoretical scheme that incorporates these interrelationships that I believe will make my approach in "The nature of the firm" operational (Coase 1993a, 73).

Williamson goes a step further and offers a complex and rather complete analysis of the determinants of the mode of making transactions. First, he claims that:

[...] the advantages of integration thus are not that technological (flow process) economies are unavailable to nonintegrated firms, but that integration harmonizes interests (or reconciles differences, often by fiat) and permits an efficient (adaptive, sequential) decision making process (Williamson 1971, 117).

Thus, economizing on transaction costs matters for selecting a given way of contracting. Although his work from the early 1970s was stimulated by empirical research, his papers from that period were of purely theoretical character. His aim was to build a conceptual framework which only later could be used as a tool in empirical research. The purpose of his subsequent articles (1971; 1973; 1975; 1979) was to conceptualize the interplay between various factors responsible for vertical integration.

This was done in my article "Transaction cost economics: the governance of contractual arrangements" [...]. I think this is a key article [...]. This effort to so to speak "dimensionalize transactions" seemed to me at that time and since as an important step on the 
road of operationalizing this whole line of study (Williamson 1990, 120).

Although Williamson's 1979 paper shows the impact of asset specificity on the choice of organizational form, it does not elaborate on the interplay between the imperative of transaction costs minimization and the neoclassical rule of optimizing the size of production activity (economizing on production costs). In other words, he does not conceptualize the relation between asset specificity and the total production costs-neoclassical production costs plus transaction costs-(Menard 2007). That was due to his negligence of technological issues: "concentrating on the study of transaction technology resulted in disregarding the role of production technology" (Williamson 1988, 361).

In the late 1970s and the early 1980s he re-discovered the role of production technology in defining the mode of making transactions and hence the concept of asset specificity: naturally related to production technology, started to play a dominant role in the explanans of his theory. In his 1981 paper he writes:

If assets are nonspecific, markets enjoy advantages in both production cost and governance cost respects: static scale economies can be more fully exhausted by buying instead of making; markets can also aggregate uncorrelated demands, thereby realizing risk-pooling benefits; and external procurement avoids many of the hazards to which internal procurement is subject. As assets become more specific, however, the aggregation benefits of markets in the first two respects are reduced and exchange takes on a progressively stronger bilateral character (Williamson 1981a, 558).

Simply speaking, Williamsonian TCE treats the firm as an avoider of negatives (Conner 1991). First, as an avoider of high exchange costs on the market. Second, as an avoider of the risks resulting from the holdup problem. Third, as an avoider of opportunistic market relations. Since at the heart of Williamsonian TCE there is an assumption that "the same production activities can be carried on either within the firm or by a collection of autonomous contractors-that is except for problems of opportunism, the same inputs can be used equally productively in a firm or a market context" (Conner 1991, 142).

It is really hard to see here the firm as a creator of any positive value. That is contrary to earlier views of the firm such as that of the resource based literature that claimed that firm specific assets are more 
productive inside than outside the firm (e.g., Wernerfelt 1984). In the Williamsonian framework, if we do not have any opportunism, then any resource can be used with the same productivity within or outside the firm. Going even further, one could say that in the situation of the nonexistence of opportunism, there would not be any reason for the emergence of the firm, but the actual nature of economic systems proves the contrary: firms emerge even when one cannot identify any opportunistic behavior.

The reason why Williamson treats the firm as an avoider of negatives lies in the fact that economists of organization focus their attention only on the role of the firm in constraining rent-seeking behavior resulting from imperfect knowledge (Langlois and Foss 1997, 6). They do not elaborate on the role of the firm in productive rent-seeking, namely the more efficient use of knowledge. "Economists have neglected the benefit side of alternative organizational structures; for reasons of history and technique, they have allocated most of their resources to the cost side" (Langlois and Foss 1997, 6).

In his early literature on TCE, Williamson concentrated on the issue of coordination: firms emerge in order to facilitate cooperation between various production inputs. In other words, firms materialize in order to avoid the market costs of coordination which are quite high in the case of boundedly rational agents confronting uncertainty.

If, in consideration of these [cognitive] limits [resulting from bounded rationality], it is very costly or impossible to identify future contingencies and specify, ex ante, appropriate adaptations thereto, long-term contracts may be supplanted by internal organization [...]. Internal organization in this way economizes on the bounded rationality attributes of decision makers in circumstances in which prices are not "sufficient statistics" and uncertainty is substantial (Williamson 1975, 9).

Williamson summarizes his research strategy as follows: "A useful strategy for explicating the decision to integrate is to hold technology constant across alternative modes of organization and to neutralize obvious sources of differential economic benefit" (Williamson 1985, 88). So, in his work from the 1970s and the 1980s he neglected the role of firm-specific knowledge, i.e., the positive capabilities of a firm. He assumed that knowledge could be equally well transmitted between parties transacting on the market and those transacting internally. That claim is related to the ME assumption that firm behaviour-e.g., profit 
maximization-is invariant to its institutional form-e.g., ownership structure-(Foss, et al. 1999, 632). In the next section, I show that a departure from that very assumption of Williamsonian TCE opens the door for a new kind of theory of the firm in which an enterprise is treated as a creator of positive value.

\section{THE SECOND COGNITIVE TURN}

I have shown already that the first cognitive turn in economics was associated with the work of Simon and others from Carnegie. The role of TCE in this turn was to offer a link between neoclassical economics and cognitive psychology combined with Carnegie's organizational theory, e.g., TCE popularized the concept of bounded rationality in ME (Foss 2003). ${ }^{10}$ In that sense, TCE played a significant role in making the economics of the 1970s more diversified. However, it did not incorporate into its explanans all the concepts and theories of the economics of information and cognitive psychology: "Williamson has taken only part of Simon's argument on board” (Hodgson 1993, 11).

TCE, for instance, neglects the role of knowledge formation and sharing in defining the way transactions are organized. Williamson's contributions from the 1970s implicitly assumed that knowledge can be equally well shared on the market and within the firm. It should be noted that even in the pre-Williamsonian theory many claimed that knowledge can be more easily transmitted within the firm (Malmgren 1961). That is due to the fact that knowledge often has a tacit nature and needs a stable environment to be efficiently shared: "the more often a particular transaction is made the more information the firm may have about that transaction" (Malmgren 1961, 414). That is not the case in anonymous market transactions. Such ways of understanding the economic role of the firm (half-) opened the door for theories conceptualizing the firm as a creator of positive value.

The introduction of knowledge issues into various theories of the firm, including TCE, has transformed the treatment of firms in economics (Grant 1996). For Williamson the way transactions are organized depends on asset specificity, uncertainty, and frequency of

\footnotetext{
${ }^{10}$ An interesting explanation of why Williamson built a "link" between ME and Simon's approach is offered by Pessali (2006). He uses a rhetorical analysis to show that the goal of Williamson was to persuade an ME audience to take his theory seriously and thus he had to relate TCE to their beliefs (Pessali 2006, 48). That is why, in his opinion, Williamsonian TCE shares some fundamental assumptions with ME (e.g., cost minimization).
} 
contracting. When the focus is on knowledge, the three pillars of Williamsonian TCE do not offer a sufficient basis for predicting the emerging organizational form. It is quite intuitive that in the case of interactions rich in knowledge special governance structures should emerge. In the beginning of the 1990s it became evident that in a modern economy what really matters are the knowledge transactions (e.g., Starbuck 1992; for the study of knowledge intensive firms). But the way transactions are conceptualized in TCE is "at best incomplete for the purpose of treating knowledge transactions" (Foss 2006, 18).

According to Winter (1987), knowledge transactions can be conceptualized in terms of the characteristics of the underlying knowledge. Following from this, he offers four dimensions of knowledge transactions: tacitness versus explicitness, system quality versus standalone, teachability versus non-teachability, and complexity versus noncomplexity. What follows is the so-called knowledge governance approach (KGA) which focuses on the problem of how to organize transactions to efficiently generate knowledge and capabilities (Nickerson and Zenger 2004, 617).

In the Coasian terminology a firm is an "island of conscious power in the ocean of market transactions" (Coase 1937, 5), and the reason for the existence of such islands is to economize on transaction costs. If we are to use the terminology of KGA, and particularly of the modularity literature, one can describe the process of firm formation as putting the interactions (transactions) within a single module: more precisely, a firm is a set of interactions (processes) that cannot be decomposed. A standard example, noted by Simon $(1962,470)$, is of the Tempus, a traditional Swiss watchmaker, who manufactured all the parts of a watch single-handedly without using any subassemblies supplied by external firms. The main reason for that specific way of organizing the production process is in the character of the underlying knowledge which is mainly of a tacit (subjective) nature. According to Langlois, "the firm exists because it offers a special kind of information exchange that somehow generates more knowledge than the 'sum' of the knowledge of participating individuals" (Langlois 2002, 34), and consequently, contrary to Williamsonian and Coasian tradition:

Firms arise as islands of nonmodularity in a sea of modularity. They may do so in response to externalities arising from the likes of team production or asset specificity. More interestingly, firms may also arise in order to generate externalities, that is, to facilitate the 
communication of rich information for purposes of qualitative coordination, innovation, and remodularization (Langlois 2002, 34).

Consequently, "firms exist because they provide a social communication of voluntaristic action structured by organizing principles that are not reducible to individuals" (Kogut and Zander 1992, 384). In the presence of knowledge rich environments what is needed for effective knowledge sharing is a common language and powerful incentives. The KGA perspective still falls within the framework of TCE because its unit of analysis is still the transaction, but now this is a knowledge transaction, and due to the very nature of knowledge (e.g., its cumulative character, tacit nature, and public good characteristics) the explanans of TCE has to be enriched. ${ }^{11}$ Since, according to the KGA approach, managers first choose valuable problems, and then the organizational mechanism that efficiently governs search (i.e., the search for knowledge), the character of a given problem is an important factor in determining the organizational choice. It should be noted here that the explanandum of TCE is still the same, i.e., at the heart of TCE is the question of how particular transactions should be organized.

If we have a decomposable problem (e.g, building a highperformance PC can be decomposed into manufacturing a high-speed processor, disk, and so on), the quality of the solution depends very little on interactions between knowledge sets (e.g., between the knowledge of the processor manufacturer and the knowledge of the hard disk manufacturer), and hence 'directional search' is best. Directional search is a search through trial and error, e.g., we put a given processor and a hard disk together and check whether we get a more efficient computer or not.

The contrary holds for non-decomposable problems, i.e., problems with intense interactions between knowledge sets such that knowledge sets cannot be separated into sub-problems, e.g., manufacturing a computer processor itself. In such cases, "an actor familiar with a particular technology cannot predictably enhance the value of the product design based solely on the knowledge he or she possesses" (Nickerson and Zenger 2004, 620). In this case 'heuristic search' is best, i.e., "trials are thus selected based on a cognitive map or implicit theory of how knowledge sets and specific design choices relevant to the

\footnotetext{
${ }^{11}$ For an in-depth analysis of the characteristics of knowledge, see Foray 2004.
} 
problem interact to determine solution performance" (Nickerson and Zenger 2004, 621).

Therefore, when problems are non-decomposable, searching best takes place within the firm, and when they are decomposable the market will be a more efficient machine for organizing searching. In this approach the firm is able to produce valuable knowledge (or, in other words, to solve valuable problems). The language of Nickerson and Zenger's theory is taken from the work of Simon, e.g., the concept of non-decomposable problems was introduced by Simon (1962). The late incorporation of these ideas into TCE is due to the fact that these concepts needed a designation-knowledge-which the TCE of the 1970s was not sufficiently focused on. Thus, the incorporation of Simon's legacy into the theory of TCE took nearly thirty years. From this perspective the move from TCE defining the firm as an avoider of negatives towards the view of the firm as a creator of positives is not due to the incorporation into TCE of a totally new set of theories or concepts but rather to a more complete assimilation of the Carnegie legacy. Consequently, this transformation of TCE is considered here as its second cognitive turn because defining the economic role of the firm in a positive sense has radically changed the explanans of TCE.

It should be noted also that the growing importance of knowledge issues in TCE is related indirectly to the emergence of the new behavioral economics (associated with the work of Amos Tversky and Daniel Kahneman) which deals with various sorts of cognitive biases characteristic of contracting agents (Foss 2001a, 221). One way of mitigating these biases is to use an appropriate organizational form: "[...] organization is not merely a problem [...], but organization is often a solution" (Williamson 1998, 1). A good example is the so-called availability heuristic which states that people tend to overestimate the probabilities of events they have experienced in the past. Consequently, people individually tend to make systematic errors in risk assessments. However, when put together within the framework of a firm, they start to estimate risk in more objective ways thanks to those different individual experiences. Thus, by employing a specific organizational form (the firm), the negative effects of the biases caused by the availability heuristic can be reduced. ${ }^{12}$

This second cognitive turn in TCE also follows the development of so-called cognitive economics, for which:

\footnotetext{
${ }^{12}$ For more examples, see Foss 2001b.
} 
Cognition is not only about learning processes in the human brain, but also about external knowledge storage devices, asymmetric distribution of knowledge between individuals and the organization of communication between them (Martens 2004, 7).

Since the concern of cognitive economics is with extending the cognitive capacity of individuals, the emergence of various organizational forms can be treated as the result of "[...] the evolutionary search for ever more cognitive economy" (Martens 2004, 10). Consequently, the need for overcoming the limited cognitive capacity of individuals has come to be seen as an important rationale for the existence of the firm and a significant factor in determining its organizational form.

Last but not least, we should note here that this understanding of a second cognitive turn in TCE is reinforced by the nearly simultaneous growth of the knowledge management (KM) literature. That research agenda takes its roots from Bell's (1973) seminal book The coming of post-industrial society, in which Bell argues that the post-industrial society is built upon knowledge rather than things (Hislop 2005, 4). In a similar vein, the role of knowledge in contemporary society and in management practice was described by Peter Drucker: "The basic economic resource [...] is no longer capital, nor natural resources, nor labor [...] It is and will be knowledge" (Drucker 1993, 7).

Knowledge based goods and services have replaced industrial products, and hence the focus of management literature has moved from analyzing production processes towards analyzing knowledge transfer and creation. This becomes evident when we analyze the content of the leading management journals: e.g., in 1990 one can find less than $20 \mathrm{KM}$ articles, but in 1998 there were nearly 170 (Scarbrough and Swan 2001, 6).

Since the role of the firm is to produce and transfer knowledge, the KM literature analyses the organizational structures of firms that facilitate these processes. Interestingly, the main research questions of the KM literature are closely related to those of the KGA approach described above. The claim that knowledge processes can be influenced by governance mechanisms integrates the KM literature and contemporary TCE, and hence reinforces the trend towards theorizing the firm as a creator of positives, in particular of knowledge. 


\section{THE CONTINUITY OF TCE}

Our discussion of the transformation of TCE would be incomplete without some methodological reflection on the continuity between the Williamsonian approach and more recent developments in the TCE literature. Is it possible to claim, for instance, that the KGA approach still lies within the now broadly defined TCE? That question touches upon the issue of what constitutes the very essence of TCE reasoning. Three arguments for continuity seem compelling.

First, the crucial element of TCE's explanandum is still the question of how to organize particular transactions in order to achieve the best possible outcomes. Although the second cognitive turn in TCE has transformed TCE's explanans (i.e., we now consider more factors responsible for organizational choice), its explanandum is relatively untouched.

Second, the TCE transformed by the second cognitive turn still conceptualizes transaction activity as a human undertaking which takes place in a particular institutional framework. In other words, without institutional infrastructure making transactions would be impossible, and therefore the study of institutions matters. The analysis of the interplay between transaction costs and institutions is present in Williamsonian TCE and also in more recent theories, e.g. the modularity approach and KGA. Although transaction costs are conceptualized differently in various TCE branches, the essential meaning of that concept is the same and relates to an elementary idea describing a crucial characteristic feature of human action, namely that exchange is not a zero cost activity. Understanding the economic rationale behind broadly defined costly exchange motivated Coase's 1937 paper, Williamsonian contributions from the 1970s, and is still at the heart of TCE's research agenda. In Lovejoy's terms variations in the meaning of 'transaction costs' result from the fact that it is a "recurrent unit [idea] in many contexts" (Lovejoy 1982, 17), and also from the fact that TCE is such a diversified research program.

Third, it should be stressed that although Lakatos's 'research programmes' methodology has turned out to be of little use in analyzing the issue of overall scientific progress in economics, it can still be a reasonable perspective from which to study the structure of a given scientific program (Hands 2001, 287). Even if we do not treat TCE as a pure scientific research program in the Lakatosian sense, we can identify the hard-core's characteristics that are present in both 
Williamsonian TCE and in more recent TCE, i.e., the assumption of bounded rationality, the notion of imperfect information, and the imperative of economizing on transaction costs. Consequently, and in contrast to Groenewegen and Vromen's (1996) opinion, it seems plausible that a more pluralistic theory of economic organization can be built within, and not outside, the domain of TCE. The above-described second cognitive turn in TCE is an important step towards such a theory.

\section{CONCLUSIONS}

In a paper aimed at reconstructing the development of TCE, Ronald Coase claims the following: "It is clear to me that Williamson's influence has been immense. In a real sense, transaction cost economics, through his writing and teaching, is his creation" (Coase 1993b, 98). However, as I showed briefly in the introduction, TCE is not only due to the work of Williamson, but also to various attempts to conceptualize the idea of "costly exchange". But Coase is certainly right in underlining the role of Williamson in the rise of TCE and in making its history. It was Williamson who built a theoretical bridge between neoclassical economics and Simon's approach, but he did not offer a complete synthesis of these research traditions.

The explanatory power of Williamsonian TCE lies essentially in the combination of the neoclassical logic of cost minimization (here: of transaction costs) with Simon's emphasis on the effects of bounded rationality, i.e., "[...] it is only because individual human beings are limited in knowledge, foresight, skill, and time that organizations are useful instruments for the achievement of human purpose" (Simon 1957a, 199). Therefore, TCE is situated at the intersection of economics and organization, and its contemporary development can be understood as a move from defining the firm as an avoider of negatives (i.e., of transaction costs, and other negative effects of bounded rationality) towards viewing the firm as a creator of positives. That move is due to the growing interest of economics in knowledge issues.

Interestingly, that process has redirected the attention of TCE back towards Simon's theory. Moreover, TCE has benefitted a lot from the recent developments in the cognitive sciences in which the firm has come to be seen as an important device for extending the cognitive capacity of individual economic agents. TCE may again play a crucial role in transforming modern economics just as it did in the 1970s, and 
the second cognitive turn in TCE may make that approach a real synthesis of neoclassicism and modern organizational theory (Dugger 1983, 111). Consequently, the second cognitive turn in TCE may in the near future appear as a cognitive turn not only in TCE, but in economics as a whole.

\section{REFERENCES}

Allen, Douglas. 1999. Transaction costs. In Encyclopedia of law and economics, volume I: the history and methodology of law and economics, eds. Boudewijn Bouckaert, and Gerrit de Geest. Cheltenham: Edward Elgar, 894-926.

Augier, Mie, and James March (eds.). 2002. The economics of choice, change and organization: essays in memory of Richard M. Cyert. Cheltenham: Edward Elgar.

Bachelard, Gaston. 1951. L'actualité de l'histoire des sciences. Paris: Palais de la Découverte.

Bell, Daniel. 1973. The coming of post-industrial society. Harmondsworth: Penguin.

Bernard, Chester. 1938. The functions of the executive. Cambridge (MA): Harvard University Press.

Coase, Ronald. 1937. The nature of the firm. Economica, 4 (16): 336-405.

Coase, Ronald. 1993a. The nature of the firm: influence. In The nature of the firm: origins, evolution, and development, eds. Oliver Williamson, and Sydney Winter. Oxford: Oxford University Press, 61-74.

Coase, Ronald. 1993b. Coase on Posner on Coase. Journal of Institutional and Theoretical Economics, 149 (1): 96-98.

Colander, David, Richard Holt, and Barkley Rosser. 2004. Changing face of economics: conversations with cutting edge economists. Ann Arbor: University of Michigan Press.

Conner, Kathleen. 1991. A historical comparison of resource-based theory and five schools of thought within industrial organization economics: do we have a new theory of the firm? Journal of Management, 17 (1): 121-154.

Cyert, Richard, and James March. 1964. A behavioral theory of the firm. Englewood Cliffs (NJ): Prentice-Hall.

Drucker, Peter. 1993. Post-capitalist society. Oxford: Butterworth-Heinemann.

Dugger, William. 1983. The transaction cost analysis of Oliver E. Williamson: a new synthesis? Journal of Economic Issues, 17 (1): 95-114.

Foray, Dominique. 2004. The economics of knowledge. Cambridge (MA): MIT Press.

Foss, Nicolai. 1996. The emerging knowledge governance approach: challenges and characteristics. DRUID Working Paper No. 06-10. Copenhagen Business School, Copenhagen.

Foss, Nicolai. 2001a. Simon's grand theme and the economics of organization: a note for a roundtable on cognition, rationality and governance, dedicated to the memory of Herbert A. Simon. Journal of Management and Governance, 5 (3): 216223.

Foss, Nicolai. 2001b. Bounded rationality in the economics of organization: present use and (some) future possibilities. Journal of Management and Governance, 5 (3): 401-425. 
Foss, Nicolai. 2003. The rhetorical dimensions of bounded rationality: Herbert A. Simon and organizational economics. In Cognitive developments in economics, ed. Salvatore Rizzello. London: Routledge, 158-176.

Foss, Nicolai, Henrik Lando, and Steen Thomsen. 1999. The theory of the firm. In Encyclopedia of law and economics, volume I: the history and methodology of law and economics, eds. Boudewijn Bouckaert, and Gerrit de Geest. Cheltenham: Edward Elgar, 631-658.

Gordon, Robert. 1948. Short-period price determination in theory and practice. American Economic Review, 38 (3): 265-288.

Grant, Robert M. 1996. Toward a knowledge-based theory of the firm. Strategic Management Journal, 17 (special issue): 109-122.

Groenewegen, John, and Jack Vromen (eds.). 1996. Transaction cost economics and beyond. Boston: Kluwer.

Hands, D. Wade. 2001. Reflection without rules: economic methodology and contemporary science theory. Cambridge: Cambridge University Press.

Hardt, Łukasz. 2006. Transaction cost economics as a three dimensional externally driven research program. Studia Ekonomiczne, 2006 (1-2): 7-31.

Hicks, John. 1935. A suggestion for simplifying the theory of money. Economica, 2 (5): 1-19.

Hislop, Donald. 2005. Knowledge management in organizations: a critical introduction. Oxford: Oxford University Press.

Hodgson, Geoffrey. 1993. Institutional economics: surveying the 'old' and the 'new'. Metroeconomica, 44 (1): 1-28.

Holmstrom, Bengt, and Jean Tirole. 1989. The theory of the firm. In Handbook of industrial organization, eds. Richard Schmalensee, and Robert Willing. Amsterdam: Elsevier Science, 61-133.

Katona, George. 1951. Psychological analysis of economic behavior. New York: McGrawHill.

Klaes, Matthias. 2000a. The history of the concept of transaction costs: neglected aspects. Journal of the History of Economic Thought, 22 (2): 191-216.

Klaes, Matthias. 2000b. The birth of the concept of transaction costs: issues and controversies. Industrial and Corporate Change, 9 (4): 567-593.

Klaes, Matthias. 2001a. Begriffsgeschichte: between the Scylla of conceptual and the Charybdis of institutional history of economics. Journal of the History of Economic Thought, 23 (2): 153-179.

Klaes, Matthias. 2001b. Transaction cost economics: shifting alliances. Paper presented at the 2001 EAEPE conference.

Kogut, Bruce, and Udo Zander. 1992. Knowledge of the firm, combinative capabilities, and the replication of technology. Organization Science, 3 (3): 383-397.

Kurz, Mordecai. 1974. Equilibrium in finite sequence of markets with transaction cost. Econometrica, 42 (1): 1-20.

Langlois, Richard. 2002. Modularity in technology and organization. Journal of Economic Behavior \& Organization, 49 (1): 19-37.

Langlois, Richard, and Nicolai Foss. 1997. Capabilities and governance: the rebirth of production in the theory of economic organization. DRUID Working Paper No. 972. Copenhagen Business School, Copenhagen. 
Lovejoy, Arthur. 1982. The great chain of being: a study of the history of an idea. Cambridge (MA): Harvard University Press.

Mäki, Uskali. 1997. The one world and many theories. In Pluralism in economics: new perspectives in history and methodology, eds. Andrea Salanti, and Ernesto Screpanti. Cheltenham: Edward Elgar, 37-47.

Malmgren, Harold. 1961. Information, expectations, and the theory of the firm. Quarterly Journal of Economics, 75 (3): 398-421.

Margolis, Julius. 1958. The analysis of the firm: rationalism, conventionalism, and behaviorism. The Journal of Business, 31 (3): 187-199.

Martens, Bertin. 2004. The cognitive mechanisms of economic development and institutional change. London: Routledge.

Menard, Claude. 2007. A new institutional approach to organization. In Handbook of new institutional economics, eds. Claude Menard, and Mary Shirley. New York: Springer, 281-318.

Mirowski, Philip. 2001. Machine dreams: economics becomes a cyborg science. Cambridge: Cambridge University Press.

Nickerson, Jackson, and Todd Zenger. 2004. A knowledge-based theory of the firm: the problem-solving perspective. Organization Science, 15 (6): 617-632.

Papandreou, Andreas. 1952. Some basic issues in the theory of the firm. In A survey of contemporary economics, ed. Bernard F. Haley. Homewood (IL): Richard D. Irwin, Inc., 183-219.

Pessali, Huascar. 2006. The rhetoric of Oliver Williamson's transaction cost economics. Journal of Institutional Economics, 2 (1): 45-65.

Rothschild, Kurt. 1947. Price theory and oligopoly. Economic Journal, 57 (227): 299320.

Salanti, Andrea, and Ernesto Screpanti. 1997. Pluralism in economics: new perspectives in history and methodology. Cheltenham: Edward Elgar.

Scarbrough, Harry, and Jacky Swan. 2001. Explaining the diffusion of knowledge management: the role of fashion. British Journal of Management, 12 (1): 3-12.

Scitovsky, Tibor. 1940. A study of interest and capital. Economica, 7 (27): 293-317.

Sent, Esther-Mirjam. 2004. Behavioral economics: how psychology made its (limited) way back into economics. History of Political Economy. 36 (4): 735-760.

Sent, Esther-Mirjam. 2006. Pluralisms in economics. In Scientific pluralism, eds. S. Kellert, H. Longino, and K. Waters. Minnesota Studies in the Philosophy of Science, Minneapolis (MN): University of Minnesota Press, 80-101.

Simon, Herbert. 1957a. Models of man. New York: John Wiley and Sons.

Simon, Herbert. 1957b [1947]. Administrative behaviour. New York: Macmillan.

Simon, Herbert. 1962. The architecture of complexity. Proceedings of the American Philosophical Society, 106 (6): 467-482.

Simon, Herbert. 1978. Rationality as process of and as product of thought. American Economic Review, 68 (2): 1-16.

Simon, Herbert. 1991. Models of my life. New York: Basic Books.

Simon, Herbert. 1997. An empirically based microeconomics. New York: Cambridge University Press.

Simon, Herbert, Donald Smithburg, and Victor Thompson. 1950. Public administration. New York: Knopf. 
Walras, Léon. 1893. To Johan Gustave Knut Wicksell (letter no. 1170). In Correspondence of Léon Walras and related papers, vol. II (1884-1897), ed. William Jaffé. Amsterdam: Royal Netherlands Academy of Sciences and Letters.

Wernerfelt, Birger. 1984. A Resource-Based View of the Firm. Strategic Management Journal, 5 (2): 171-180.

Williamson, Oliver. 1967. Hierarchical control and optimum firm size. Journal of Political Economy, 75 (2): 123-138.

Williamson, Oliver. 1971. The vertical integration of production: market failure considerations. American Economic Review, 61 (2): 112-123.

Williamson, Oliver. 1973. Markets and hierarchies: some elementary considerations. American Economic Review, 63 (2): 316-325.

Williamson, Oliver. 1975. Markets and hierarchies: analysis and antitrust implications. New York: The Free Press.

Williamson, Oliver. 1979. Transaction cost economics: the governance of contractual relations. Journal of Law and Economics, 22 (2): 233-261.

Williamson, Oliver. 1981a. The economics of organization: the transaction cost approach. The American Journal of Sociology, 87 (3): 548-577.

Williamson, Oliver. 1981b. The modern corporation: origins, evolution, attributes. Journal of Economic Literature, 19 (4): 1537-1568

Williamson, Oliver. 1985. The economic institutions of capitalism. New York: The Free Press.

Williamson, Oliver. 1988. Technology and transaction cost economics: a reply. Journal of Economic Behavior and Organization, 10 (3): 355-363.

Williamson, Oliver. 1990. Interview. In Economics and sociology: redefining their boundaries, ed. Richard Swedberg. Princeton (NJ): Princeton University Press, 115129.

Williamson, Oliver. 1996. Transaction cost economics and the Carnegie connection. Journal of Economic Behavior \& Organization, 31 (2): 149-155.

Williamson, Oliver. 1998. Human actors and economic organization. Paper presented at the 1998 ISNIE conference.

Winter, Sidney. 1987. Knowledge and competence as strategic assets. In The competitive challenge, ed. D. Teece. Cambridge (MA): Ballinger, 159-184.

Lukasz Hardt is an assistant professor at the Department of Economics, University of Warsaw. He also works at the Institute of Economics, at the Polish Academy of Sciences. He is particularly interested in the history of transaction cost economics, institutional economics, and the theory of the firm. In addition, he has written papers analyzing the economic transformation of Poland from the perspective of new institutional economics.

Contact e-mail: <lhardt@wne.uw.edu.pl> 